\title{
Synthesis and Thermal Properties of Main Chain Polyimides Containing Chalcone Derivative
}

\author{
Takashi MiHARA, Yousuke NAKAO, and Naoyuki KoIDE ${ }^{\dagger}$ \\ Department of Chemistry, Faculty of Science, Tokyo University of Science, \\ 1-3 Kagurazaka, Shinjuku-ku, Tokyo 162-8601, Japan
}

(Received June 3, 2004; Accepted August 23, 2004; Published November 15, 2004)

\begin{abstract}
We synthesized main chain polyimides containing photosensitive chalcone moiety and investigated thermal properties of the polyimides. The polyimides were prepared by acid anhydrides $\left[4,4^{\prime}\right.$-(hexafluoro-isopropylidene) diphthalic anhydride (6FDA) or 4,4'-biphthalic anhydride (BPDA)] and diamine derivatives containing a chalcone group. The polyimides with 6FDA derivative were soluble in organic solvents such as tetrahydrofuran, chloroform and $\mathrm{N}, \mathrm{N}$-dimethylformamide. On the other hand, the polyimides with BPDA derivative were insoluble in common organic solvents. The polyimides with 6FDA derivative did not exhibit any mesophases, while the polyimides with BPDA derivative displayed a smectic phase. [DOI 10.1295/polymj.36.899]

KEY WORDS Chalcone / Liquid Crystalline Polymer / Soluble Polyimide /
\end{abstract}

The alignment of liquid crystalline (LC) molecules plays an important role for liquid crystalline displays (LCDs). The rubbing process has been mainly employed for the uniaxial orientation of the LC molecules. However, the rubbing process has many disadvantages for LCDs such as generation of electrostatic charge and dust. Therefore, many methods of alignment technique for LC molecules are focused on rubbing free methods. Photo-alignment procedure is recognized as one of rubbing free methods and has been investigated as one of candidates that overcome the generation of electrostatic charge and dust for the rubbing process. ${ }^{1,2}$

The photo-alignment procedure is based on photochemical reactions such as photo-isomerization, photo-dimerization (photo-crosslinking) and photodecomposition of the photosensitive group. ${ }^{3-5}$ In general, photo-dimerization of photosensitive groups in polymers is employed to obtain a stable alignment of LC molecules. ${ }^{2,6-10}$ It would be desirable that photo-dimerization occurs by the exposure of relatively longer wavelength of the UV light to avoid partial degradation of polymer main chain by the irradiation. ${ }^{11}$ It is well known that the photoreaction of chalcone moieties takes place by the irradiation with relatively longer wavelength of the UV light. Photosensitive polymers containing chalcone derivatives have been studied for the photo-alignment film. ${ }^{11-17}$

The alignment behavior of the LC molecules would be easily improved by the liquid crystalline polymer surface where mesogenic groups existed, because the chemical structure of the mesogenic groups is similar to that of the LC molecules. ${ }^{18,19} \mathrm{We}$ already investigated thermal and photo-alignment properties of side chain LC methacrylate polymers and side chain polyimides bearing the chalcone derivative in the side chain. ${ }^{20-22}$ However, main chain polymers with a chalcone derivative are little investigated. ${ }^{23,24}$

Polyimides exhibit good thermal and mechanical properties based upon the rigid rod-like chemical structure of the polymer backbone. Polyimides would be a suitable candidate for the polymeric materials applied to the photo-alignment film, because rubbed polyimide films are actually used as the alignment film in the LCDs.

The purpose of this study is to synthesize liquid crystalline chalcone-based soluble polyimides. To obtain chalcone-based soluble polyimides, we employed two acid anhydrides [4,4'-(hexafluoro-isopropylidene)-diphthalic anhydride (6FDA) or 4,4'-biphthalic anhydride (BPDA)] and diamine derivatives containing a chalcone derivative.

\section{EXPERIMENTAL}

\section{Materials}

Synthesis of intermediates and main chain polyimides was described in Schemes 1-4. 4-(Tetrahydropyran-2-yloxy) benzaldehyde (1), 4-(Tetrahydropyran-2-yloxy)acetophenone (2), 4,4'-(tetrahydropyran2-yloxy) chalcone (3), 4,4'-dihydroxychalcone (4) were synthesized according to the literature. ${ }^{24} 4-[11-$ (Tetrahydropyran-2-yloxy)undecyloxy] benzoic acid (8) was prepared according to the conventional synthetic method of liquid crystalline monomers. Synthetic procedures of other compounds were described below.

${ }^{\dagger}$ To whom correspondence should be addressed (Tel: +81-3-5228-8248, Fax: +81-3-3235-2214, E-mail: nkoide@ch.kagu.sut.ac.jp). 


\title{
Synthesis and Thermal Properties of Main Chain Polyimides Containing Chalcone Derivative
}

\author{
Takashi MiHARA, Yousuke NAKAO, and Naoyuki KoIDE ${ }^{\dagger}$ \\ Department of Chemistry, Faculty of Science, Tokyo University of Science, \\ 1-3 Kagurazaka, Shinjuku-ku, Tokyo 162-8601, Japan
}

(Received June 3, 2004; Accepted August 23, 2004; Published November 15, 2004)

\begin{abstract}
We synthesized main chain polyimides containing photosensitive chalcone moiety and investigated thermal properties of the polyimides. The polyimides were prepared by acid anhydrides $\left[4,4^{\prime}\right.$-(hexafluoro-isopropylidene) diphthalic anhydride (6FDA) or 4,4'-biphthalic anhydride (BPDA)] and diamine derivatives containing a chalcone group. The polyimides with 6FDA derivative were soluble in organic solvents such as tetrahydrofuran, chloroform and $\mathrm{N}, \mathrm{N}$-dimethylformamide. On the other hand, the polyimides with BPDA derivative were insoluble in common organic solvents. The polyimides with 6FDA derivative did not exhibit any mesophases, while the polyimides with BPDA derivative displayed a smectic phase. [DOI 10.1295/polymj.36.899]

KEY WORDS Chalcone / Liquid Crystalline Polymer / Soluble Polyimide /
\end{abstract}

The alignment of liquid crystalline (LC) molecules plays an important role for liquid crystalline displays (LCDs). The rubbing process has been mainly employed for the uniaxial orientation of the LC molecules. However, the rubbing process has many disadvantages for LCDs such as generation of electrostatic charge and dust. Therefore, many methods of alignment technique for LC molecules are focused on rubbing free methods. Photo-alignment procedure is recognized as one of rubbing free methods and has been investigated as one of candidates that overcome the generation of electrostatic charge and dust for the rubbing process. ${ }^{1,2}$

The photo-alignment procedure is based on photochemical reactions such as photo-isomerization, photo-dimerization (photo-crosslinking) and photodecomposition of the photosensitive group. ${ }^{3-5}$ In general, photo-dimerization of photosensitive groups in polymers is employed to obtain a stable alignment of LC molecules. ${ }^{2,6-10}$ It would be desirable that photo-dimerization occurs by the exposure of relatively longer wavelength of the UV light to avoid partial degradation of polymer main chain by the irradiation. ${ }^{11}$ It is well known that the photoreaction of chalcone moieties takes place by the irradiation with relatively longer wavelength of the UV light. Photosensitive polymers containing chalcone derivatives have been studied for the photo-alignment film. ${ }^{11-17}$

The alignment behavior of the LC molecules would be easily improved by the liquid crystalline polymer surface where mesogenic groups existed, because the chemical structure of the mesogenic groups is similar to that of the LC molecules. ${ }^{18,19} \mathrm{We}$ already investigated thermal and photo-alignment properties of side chain LC methacrylate polymers and side chain polyimides bearing the chalcone derivative in the side chain. ${ }^{20-22}$ However, main chain polymers with a chalcone derivative are little investigated. ${ }^{23,24}$

Polyimides exhibit good thermal and mechanical properties based upon the rigid rod-like chemical structure of the polymer backbone. Polyimides would be a suitable candidate for the polymeric materials applied to the photo-alignment film, because rubbed polyimide films are actually used as the alignment film in the LCDs.

The purpose of this study is to synthesize liquid crystalline chalcone-based soluble polyimides. To obtain chalcone-based soluble polyimides, we employed two acid anhydrides [4,4'-(hexafluoro-isopropylidene)-diphthalic anhydride (6FDA) or 4,4'-biphthalic anhydride (BPDA)] and diamine derivatives containing a chalcone derivative.

\section{EXPERIMENTAL}

\section{Materials}

Synthesis of intermediates and main chain polyimides was described in Schemes 1-4. 4-(Tetrahydropyran-2-yloxy) benzaldehyde (1), 4-(Tetrahydropyran-2-yloxy)acetophenone (2), 4,4'-(tetrahydropyran2-yloxy) chalcone (3), 4,4'-dihydroxychalcone (4) were synthesized according to the literature. ${ }^{24} 4-[11-$ (Tetrahydropyran-2-yloxy)undecyloxy] benzoic acid (8) was prepared according to the conventional synthetic method of liquid crystalline monomers. Synthetic procedures of other compounds were described below.

${ }^{\dagger}$ To whom correspondence should be addressed (Tel: +81-3-5228-8248, Fax: +81-3-3235-2214, E-mail: nkoide@ch.kagu.sut.ac.jp). 


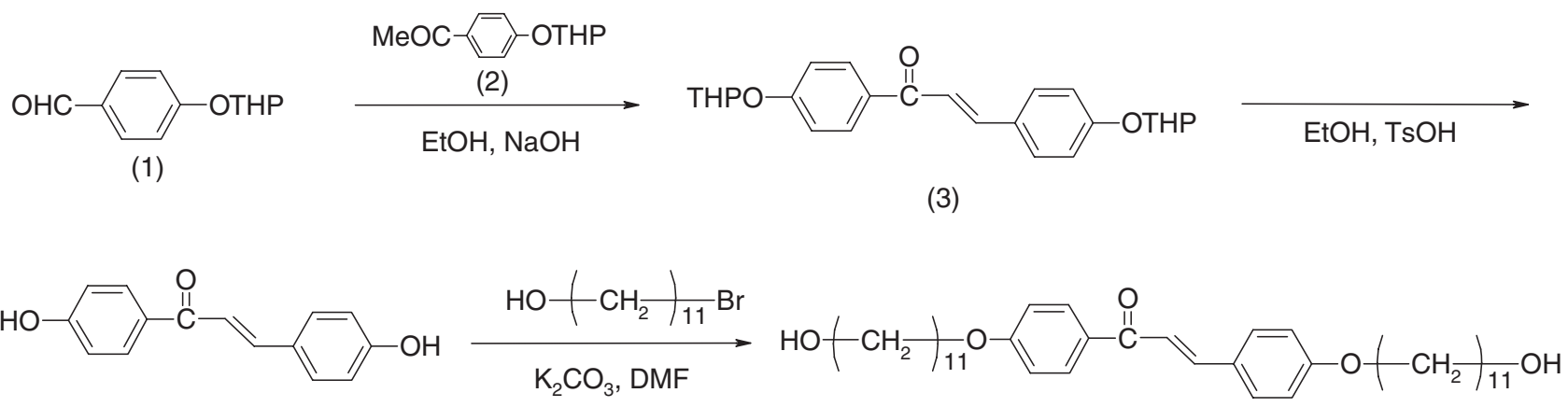

(4)

(5)

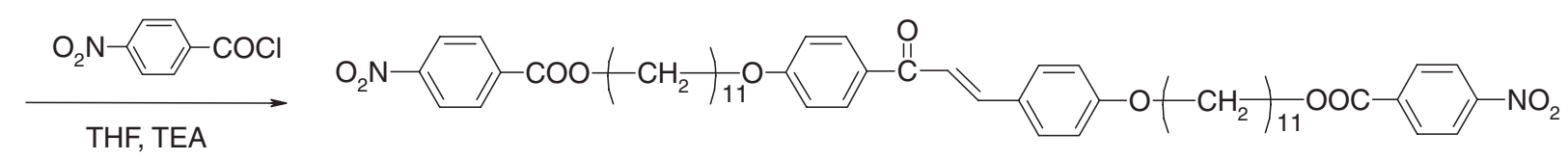

(6)

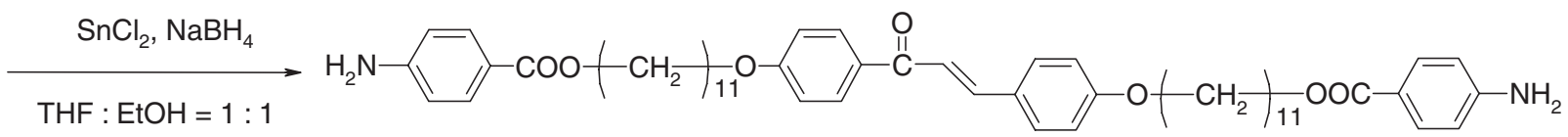

(7)

Scheme 1. Synthesis of diamine derivative (7).

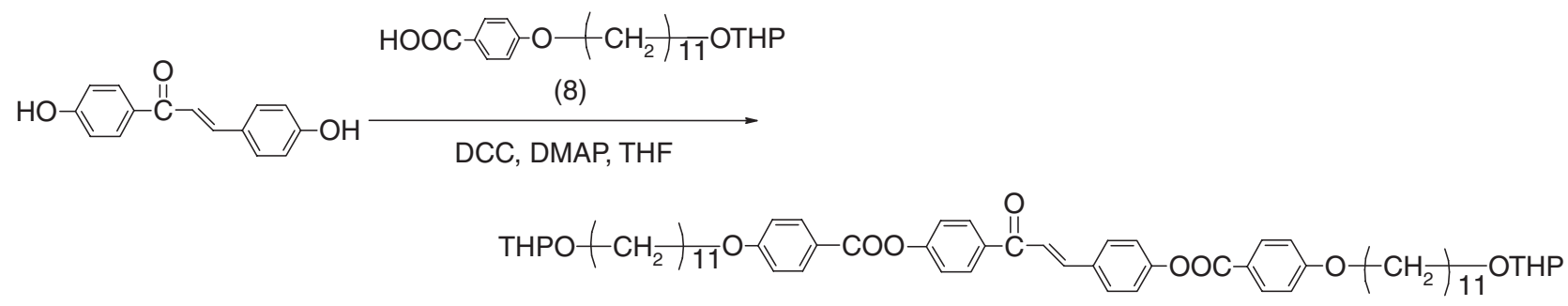

(9)

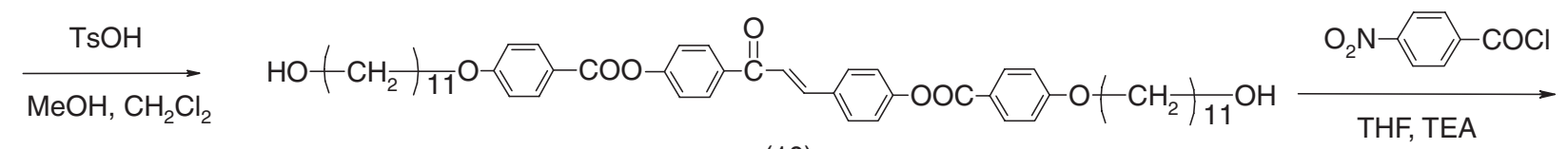

(10)

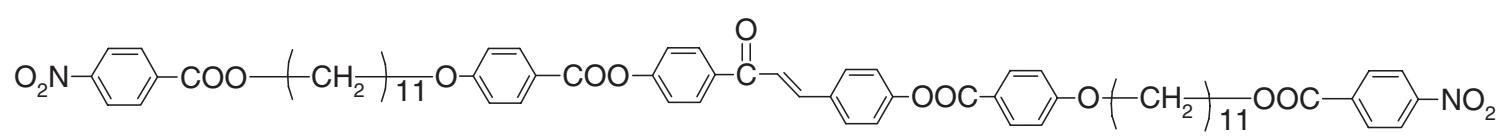

(11)

$\underset{\mathrm{SnCl}_{2}, \mathrm{NaBH}_{4}}{\longrightarrow}$

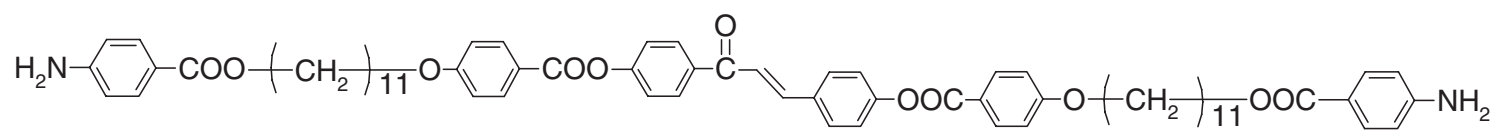

(12)

Scheme 2. Synthesis of diamine derivative (12).

4,4'-Di(hydroxyundecyloxy)chalcone (5)

4,4'-Dihydroxychalcone (4) (3.0 g, $12.5 \mathrm{mmol})$ and 11-bromoundecanol $(7.8 \mathrm{~g}, 31 \mathrm{mmol})$ were dissolved in $N, N$-dimethylformamide (DMF, $30 \mathrm{~mL}$ ). Potassium carbonate $(3.5 \mathrm{~g}, 25 \mathrm{mmol})$ and a small amount of potassium iodide were added to the DMF solution, and 

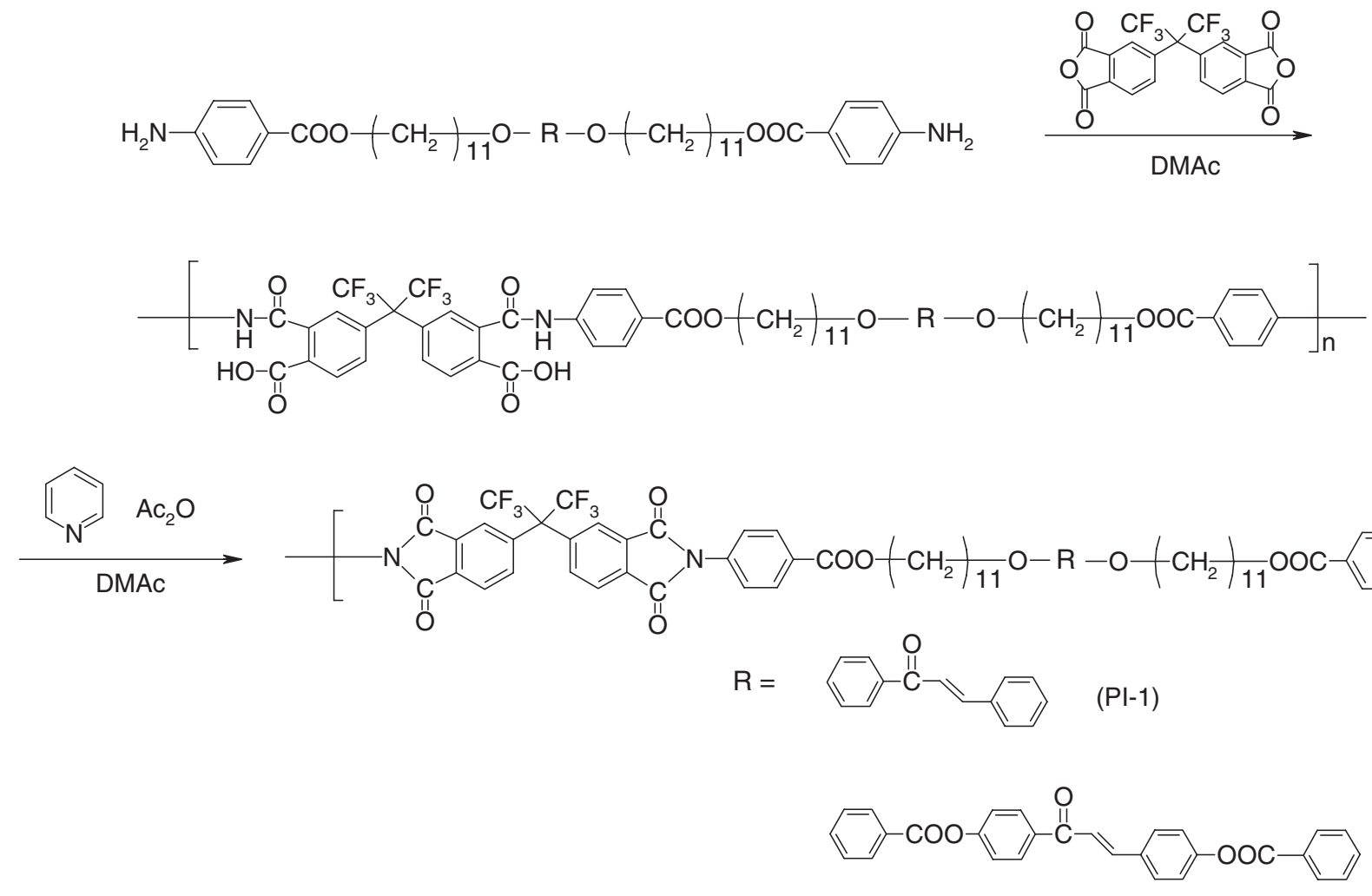

Scheme 3. Synthesis of polyimides with 6FDA derivative (PI-1 and PI-2).
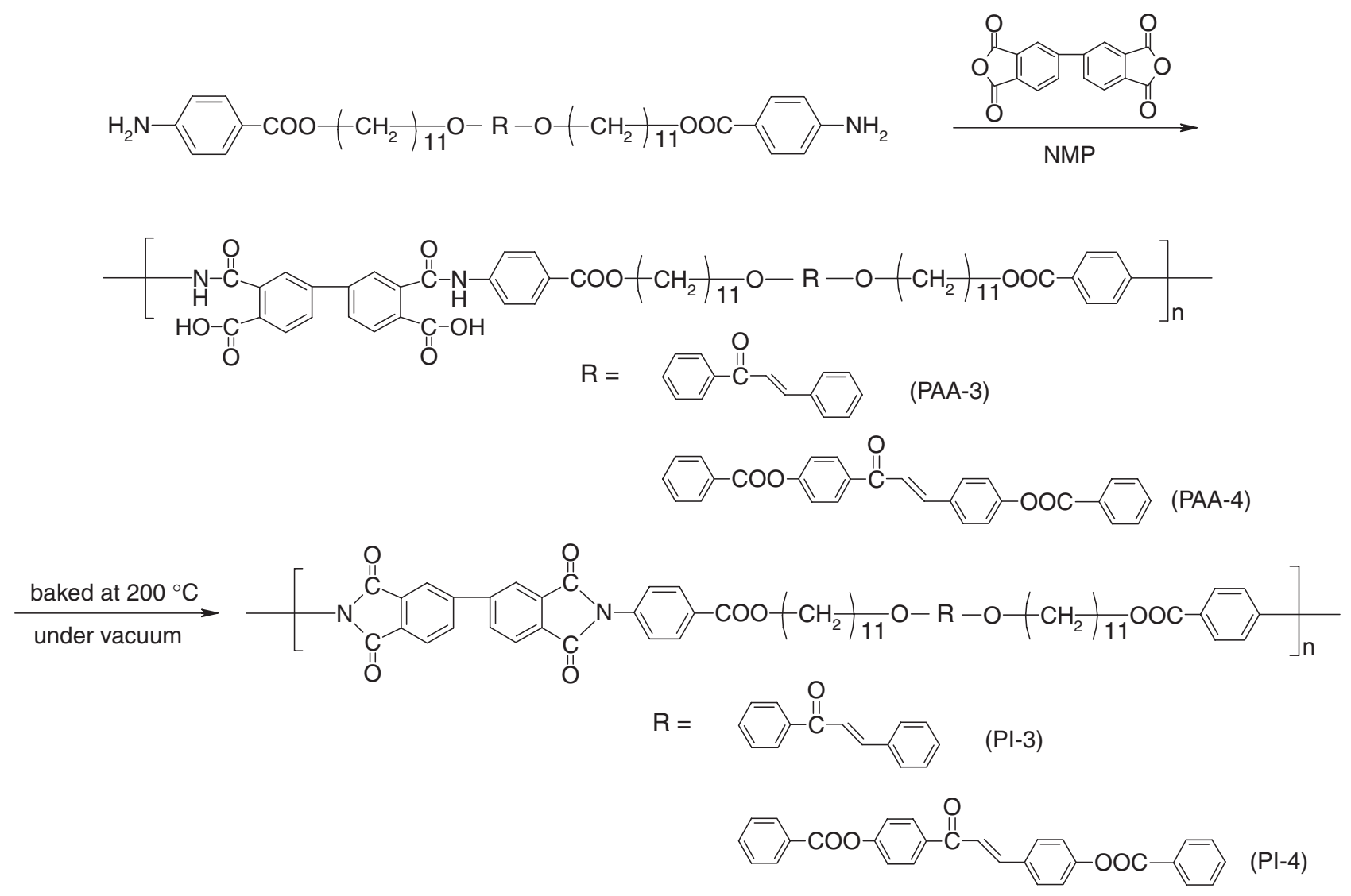

Scheme 4. Synthesis of polyimides with BPDA derivative (PI-3 and PI-4). 
then the reaction mixture was heated at $45^{\circ} \mathrm{C}$ for $3 \mathrm{~h}$. After filtration, DMF was evaporated to dryness. A solid remained was washed with hexane to remove excess 11-bromoundecanol. After the solid was washed with water, the solid was purified by recrystallization from acetone. The product was obtained in a $69 \%$ yield $\left(5.0\right.$ g). m.p. $124^{\circ} \mathrm{C}$.

${ }^{1} \mathrm{H}$ NMR $\left(\mathrm{CDCl}_{3}\right) \delta$ ppm: $1.30-1.85\left(\mathrm{~m}, 36 \mathrm{H}, \mathrm{CH}_{2}\right)$, $3.63\left(\mathrm{t}, 4 \mathrm{H},-\mathrm{OCH}_{2}\right), 4.01\left(\mathrm{~m}, 4 \mathrm{H},-\mathrm{OCH}_{2}\right), 6.9(\mathrm{q}$, $4 \mathrm{H}, \mathrm{Ar}-\mathrm{H}), 7.4(\mathrm{~d}, 1 \mathrm{H},-\mathrm{CH}=\mathrm{CH}-), 7.6(\mathrm{~d}, 2 \mathrm{H}, \mathrm{Ar}-$ $\mathrm{H}), 7.6(\mathrm{~d}, 1 \mathrm{H},-\mathrm{CH}=\mathrm{CH}-), 8.0(\mathrm{~d}, 2 \mathrm{H}, \mathrm{Ar}-\mathrm{H})$.

IR (nujol) $v \mathrm{~cm}^{-1}: 3272(-\mathrm{OH}), 1660(\mathrm{C}=\mathrm{O}), 1602$, 1510 (Ar), 989 ( $-\mathrm{CH}=\mathrm{CH}-$ ).

\section{4,4'-Di(11-nitrobenzoyloxyundecyloxy)chalcone (6)}

4,4'-Di(hydroxyundecyloxy) chalcone (5) (2.6 g, $4.5 \mathrm{mmol})$ and triethylamine $(2.8 \mathrm{~g}, 27.5 \mathrm{mmol})$ were dissolved in dry tetrahydrofuran (THF, $100 \mathrm{~mL}$ ) at $40^{\circ} \mathrm{C}$. A THF solution $(30 \mathrm{~mL})$ of $p$-nitrobenzoyl chloride $(5.1 \mathrm{~g}, 27.5 \mathrm{mmol})$ was added dropwise to the THF solution of 4,4'-di(hydroxyundecyloxy) chalcone and triethylamine at room temperature. After stirring for $24 \mathrm{~h}$ at room temperature, THF was evaporated to dryness. A solid obtained was washed with water. The solid was purified by recrystallization from acetone. The product was obtained in a $63 \%$ yield (2.5 g). m.p. $103^{\circ} \mathrm{C}$.

${ }^{1} \mathrm{H}$ NMR $\left(\mathrm{CDCl}_{3}\right) \delta \mathrm{ppm}: 1.30-1.85\left(\mathrm{~m}, 36 \mathrm{H}, \mathrm{CH}_{2}\right)$, $4.0\left(\mathrm{~m}, 4 \mathrm{H}, \mathrm{OCH}_{2}\right), 4.2\left(\mathrm{t}, 4 \mathrm{H}, \mathrm{COOCH}_{2}\right), 6.9(\mathrm{q}$, $4 \mathrm{H}, \mathrm{Ar}-\mathrm{H}), 7.4(\mathrm{~d}, 1 \mathrm{H},-\mathrm{CH}=\mathrm{CH}-), 7.6(\mathrm{~d}, 2 \mathrm{H}, \mathrm{Ar}-$ $\mathrm{H}), 7.7(\mathrm{~d}, 1 \mathrm{H},-\mathrm{CH}=\mathrm{CH}-), 8.0(\mathrm{~d}, 2 \mathrm{H}, \mathrm{Ar}-\mathrm{H}), 8.2$ $(\mathrm{d}, 4 \mathrm{H}, \mathrm{Ar}-\mathrm{H}), 8.3(\mathrm{~d}, 4 \mathrm{H}, \mathrm{Ar}-\mathrm{H})$.

IR (nujol) $v \mathrm{~cm}^{-1}$ : $1714(\mathrm{COO}), 1660(\mathrm{C}=\mathrm{O}$ in chalcone group), 1606, 1510 (Ar), $1540\left(\mathrm{NO}_{2}\right), 979$ $(-\mathrm{CH}=\mathrm{CH}-)$.

\section{4,4'-Di(11-aminobenzoyloxyundecyloxy)chalcone (7)}

4,4'-Di(11-nitrobenzoyloxyundecyloxy)chalcone (6) $(1.2 \mathrm{~g}, 1.37 \mathrm{mmol})$ was dissolved in the mixed solvent $(40 \mathrm{~mL})$ of ethanol and THF (volume ratio 1:1). Tin(II) chloride dihydrate $(3.1 \mathrm{~g}, 13.7 \mathrm{mmol})$ was added to the solution. The solution was heated at $60^{\circ} \mathrm{C}$, and then sodium borohydride $(0.05 \mathrm{~g}, 1.3 \mathrm{mmol})$ was added to the solution over a period of $30 \mathrm{~min}$. After heating for $30 \mathrm{~min}$ at $60^{\circ} \mathrm{C}$, the reaction mixture was cooled to $5-10^{\circ} \mathrm{C}$. Chilled water was added to the reaction mixture. The reaction mixture was neutralized with aqueous solution of sodium hydroxide. The solution was filtrated to remove the precipitated white solid. The filtrate was evaporated to dryness, and then the residue was purified by recrystallization from acetone. The white precipitate was extracted with THF. The THF solution was evaporated to dryness. After the residue was stirred in methanol, the residue was purified by recrystallization from acetone.
The product was obtained in a $50 \%(0.56 \mathrm{~g})$. m.p. $129^{\circ} \mathrm{C}$.

${ }^{1} \mathrm{H}$ NMR $\left(\mathrm{CDCl}_{3}\right) \delta$ ppm: $1.30-1.85\left(\mathrm{~m}, 36 \mathrm{H}, \mathrm{CH}_{2}\right)$, $4.0\left(\mathrm{~m}, 8 \mathrm{H},-\mathrm{OCH}_{2},-\mathrm{NH}_{2}\right), 4.2\left(\mathrm{~m}, 4 \mathrm{H}, \mathrm{COOCH}_{2}\right)$, $6.6(\mathrm{~d}, 4 \mathrm{H}, \mathrm{Ar}-\mathrm{H}), 6.9(\mathrm{q}, 4 \mathrm{H}, \mathrm{Ar}-\mathrm{H}), 7.4(\mathrm{~d}, 1 \mathrm{H}$, $-\mathrm{CH}=\mathrm{CH}-), 7.6(\mathrm{~d}, 2 \mathrm{H}, \mathrm{Ar}-\mathrm{H}), 7.7(\mathrm{~d}, 1 \mathrm{H},-\mathrm{CH}=$ $\mathrm{CH}-), 7.8(\mathrm{~d}, 4 \mathrm{H}, \mathrm{Ar}-\mathrm{H}), 8.0(\mathrm{~d}, 2 \mathrm{H}, \mathrm{Ar}-\mathrm{H})$.

IR (nujol) $v \mathrm{~cm}^{-1}: 3440,3357\left(\mathrm{NH}_{2}\right), 1685$ (COO), $1646(\mathrm{C}=\mathrm{O}), 1598,1511(\mathrm{Ar}), 991(-\mathrm{CH}=\mathrm{CH}-)$.

Anal. calcd for $\mathrm{C}_{51} \mathrm{H}_{66} \mathrm{~N}_{2} \mathrm{O}_{7}$ (819.10), C74.79; H8.12; N3.42. Found: C74.57; H8.12; N3.59.

\section{4,4' -Di\{4-[11-(tetrahydropyran-2-yloxy)undecyloxy]- benzoyl\} chalcone (9)}

4,4'-Dihydroxychalcone (4) $(0.8 \mathrm{~g}, 3.3 \mathrm{mmol})$, 4[11-(tetrahydropyran-2-yloxy) undecyloxy] benzoic acid (8) $(3.9 \mathrm{~g}, 9.9 \mathrm{mmol})$ and dimethylaminopyridine $(0.2 \mathrm{~g}, 1.6 \mathrm{mmol})$ were dissolved in dry THF $(20 \mathrm{~mL})$. A THF solution of dicyclohexylcarbodiimide $(3.3 \mathrm{~g}$, $16 \mathrm{mmol}$ ) was added dropwise to the THF solution. The reaction mixture was stirred for $12 \mathrm{~h}$ at room temperature. After filtration, THF was evaporated to dryness and then the residue was purified by recrystallization from acetone. The product was obtained in a $28 \%$ yield $\left(0.92\right.$ g). m.p. $121^{\circ} \mathrm{C}$.

${ }^{1} \mathrm{H}$ NMR $\left(\mathrm{CDCl}_{3}\right) \delta \mathrm{ppm}: 1.20-1.80\left(\mathrm{~m}, 48 \mathrm{H}, \mathrm{CH}_{2}\right)$, $3.4\left(\mathrm{~m}, 2 \mathrm{H}, \mathrm{OCH}_{2}\right), 3.5\left(\mathrm{~m}, 2 \mathrm{H}, \mathrm{OCH}_{2}\right), 3.7(\mathrm{~m}, 2 \mathrm{H}$, $\left.\mathrm{OCH}_{2}\right), 3.8\left(\mathrm{~m}, 2 \mathrm{H}, \mathrm{OCH}_{2}\right), 4.0\left(\mathrm{t}, 4 \mathrm{H}, \mathrm{OCH}_{2}\right), 4.5$ $\left(\mathrm{t}, 2 \mathrm{H}, \mathrm{OCH}_{2} \mathrm{O}\right), 7.0(\mathrm{~d}, 4 \mathrm{H}, \mathrm{Ar}-\mathrm{H}), 7.3(\mathrm{~d}, 2 \mathrm{H}, \mathrm{Ar}-$ $\mathrm{H}), 7.4(\mathrm{~d}, 2 \mathrm{H}, \mathrm{Ar}-\mathrm{H}), 7.6(\mathrm{~d}, 1 \mathrm{H},-\mathrm{CH}=\mathrm{CH}-), 7.7$ $(\mathrm{d}, 2 \mathrm{H}, \mathrm{Ar}-\mathrm{H}), 7.8(\mathrm{~d}, 1 \mathrm{H},-\mathrm{CH}=\mathrm{CH}-), 8.1(\mathrm{~m}, 6 \mathrm{H}$, Ar-H).

IR (nujol) $v \mathrm{~cm}^{-1}: 1727$ (COO), $1660(\mathrm{C}=\mathrm{O}$ in chalcone group), 1606 (Ar), 983 ( $-\mathrm{CH}=\mathrm{CH}-$ ).

\section{4,4' - Di [4-(11-hydroxyundecyloxy)benzoyl]chalcone} (10)

4,4'-Di $\{4$-[11-(tetrahydropyran-2-yloxy)undecyloxy]benzoyl $\}$ chalcone (9) $(1.8 \mathrm{~g}, 1.8 \mathrm{mmol})$ was dissolved in dichloromethane $(50 \mathrm{~mL})$. The methanol solution of $p$-toluenesulfonic acid $(0.30 \mathrm{~g}, 1.74 \mathrm{mmol})$ was added dropwise to the dichloromethane solution. The reaction mixture was stirred for $3 \mathrm{~h}$ at room temperature. Dichloromethane and methanol were evaporated to dryness, and then the residue was washed with water. The solid was purified by recrystallization from acetone. The product was obtained in a $66 \%$ yield (0.98 g). m.p. $158^{\circ} \mathrm{C}$.

${ }^{1} \mathrm{H}$ NMR $\left(\mathrm{CDCl}_{3}\right) \delta$ ppm: $1.20-1.80\left(\mathrm{~m}, 36 \mathrm{H}, \mathrm{CH}_{2}\right)$, $3.6\left(\mathrm{t}, 4 \mathrm{H}, \mathrm{OCH}_{2}\right), 4.2\left(\mathrm{t}, 4 \mathrm{H}, \mathrm{OCH}_{2}\right), 6.9(\mathrm{~d}, 4 \mathrm{H}$, Ar-H), 7.2 (d, 2H, Ar-H), 7.3 (d, 2H, Ar-H), 7.6 (d, $1 \mathrm{H},-\mathrm{CH}=\mathrm{CH}-), 7.8(\mathrm{~d}, 2 \mathrm{H}, \mathrm{Ar}-\mathrm{H}), 7.8(\mathrm{~d}, 1 \mathrm{H},-\mathrm{CH}=$ $\mathrm{CH}-$ ), 8.2 (d, 6H, Ar-H).

IR (nujol) $v \mathrm{~cm}^{-1}: 3334(\mathrm{OH}), 1727(\mathrm{COO}), 1664(\mathrm{C}=$ $\mathrm{O}$ in chalcone group), 1606 (Ar), $981(-\mathrm{CH}=\mathrm{CH}-)$. 
4,4'-Di\{4-[11-(4-nitrobenzoyl)undecyloxy]benzoyl\} chalcone (11)

4,4' - Di [4-(11-hydroxyundecyloxy) benzoyl] chalcone (10) $(0.98 \mathrm{~g}, 1.2 \mathrm{mmol})$ and triethylamine $(0.48$ $\mathrm{g}, 4.8 \mathrm{mmol})$ were dissolved in dry THF $(70 \mathrm{~mL})$ at $60{ }^{\circ} \mathrm{C}$. To the THF solution, the THF solution $(20 \mathrm{~mL})$ of $p$-nitrobenzoylchloride $(0.89 \mathrm{~g}, 4.8 \mathrm{mmol})$ was added dropwise at $60^{\circ} \mathrm{C}$. The reaction mixture was stirred for $12 \mathrm{~h}$ at $60^{\circ} \mathrm{C}$. THF was evaporated to dryness and then the residue was washed with water. The residue was purified by recrystallization from the mixed solvent of acetone and chloroform (volume ratio $=1: 1$ ). The product was obtained in a $52 \%$ yield (0.7 g). Cr $125 \mathrm{~N} 131 \mathrm{I}$.

${ }^{1} \mathrm{H}$ NMR $\left(\mathrm{CDCl}_{3}\right) \delta$ ppm: $1.3-1.8\left(\mathrm{~m}, 36 \mathrm{H}, \mathrm{CH}_{2}\right), 4.0$ (t, 4H, $\left.\mathrm{OCH}_{2}\right), 4.4$ (t, 4H, $\left.\mathrm{COOCH}_{2}\right), 6.9$ (d, 4H, Ar$\mathrm{H}), 7.2(\mathrm{~d}, 2 \mathrm{H}, \mathrm{Ar}-\mathrm{H}), 7.4(\mathrm{~d}, 2 \mathrm{H}, \mathrm{Ar}-\mathrm{H}), 7.5(\mathrm{~d}, 1 \mathrm{H}$, $-\mathrm{CH}=\mathrm{CH}-), 7.7(\mathrm{~d}, 2 \mathrm{H}, \mathrm{Ar}-\mathrm{H}), 7.8(\mathrm{~d}, 1 \mathrm{H},-\mathrm{CH}=$ $\mathrm{CH}-)$, 8.1-8.2 (m, 6H, Ar-H), 8.2 (d, 4H, Ar-H), $8.3(\mathrm{~d}, 4 \mathrm{H}, \mathrm{Ar}-\mathrm{H})$.

IR (nujol) $v \mathrm{~cm}^{-1}: 1716(\mathrm{COO}), 1658(\mathrm{C}=\mathrm{O}$ in chalcone group), 1604 (Ar), $1577\left(-\mathrm{NO}_{2}\right), 987(-\mathrm{CH}=$ $\mathrm{CH}-$ ).

\section{4,4'-Di\{4-[11-(4-aminobenzoyl)undecyloxy]benzoyl\}} chalcone (12)

4,4'-Di\{4-[11-(4-nitrobenzoyl)undecyloxy]benzoyl $\}$ chalcone (11) $(1.2 \mathrm{~g}, 1.07 \mathrm{mmol})$ was dissolved in the mixed solvent $(40 \mathrm{~mL})$ of ethanol and THF (volume ratio $=1: 1)$. Tin(II) chloride dihydrate $(3.1 \mathrm{~g}, 13.7$ mmol) was added to the solution. The solution was heated at $60{ }^{\circ} \mathrm{C}$, and then sodium borohydride $(0.05 \mathrm{~g}, 1.3 \mathrm{mmol})$ was added to the solution over a period of $30 \mathrm{~min}$. After heating for $30 \mathrm{~min}$ at $60^{\circ} \mathrm{C}$, the reaction mixture was cooled to $5-10^{\circ} \mathrm{C}$. Chilled water was added to the reaction mixture. The reaction mixture was neutralized with aqueous solution of sodium hydroxide. The solution was filtrated to remove the precipitated white solid. The filtrate was evaporated to dryness, and then the residue was purified by recrystallization from acetone. The precipitate was extracted with THF. The THF solution was evaporated to dryness. After the residue was stirred in methanol, the residue was purified by recrystallization from acetone. The product was obtained in a $49 \%(0.56 \mathrm{~g})$. m.p. $147^{\circ} \mathrm{C}$.

${ }^{1} \mathrm{H}$ NMR $\left(\mathrm{CDCl}_{3}\right) \delta$ ppm: $1.3-1.8\left(\mathrm{~m}, 36 \mathrm{H}, \mathrm{CH}_{2}\right), 4.0$ $\left(\mathrm{t}, 4 \mathrm{H}, \mathrm{OCH}_{2}\right), 4.2\left(\mathrm{t}, 4 \mathrm{H}, \mathrm{COOCH}_{2}\right), 6.6(\mathrm{~d}, 4 \mathrm{H}, \mathrm{Ar}-$ $\mathrm{H}), 7.0(\mathrm{~m}, 4 \mathrm{H}, \mathrm{Ar}-\mathrm{H}), 7.3(\mathrm{~d}, 2 \mathrm{H}, \mathrm{Ar}-\mathrm{H}), 7.4(\mathrm{~d}, 2 \mathrm{H}$, $\mathrm{Ar}-\mathrm{H}), 7.5(\mathrm{~d}, 1 \mathrm{H},-\mathrm{CH}=\mathrm{CH}-), 7.7(\mathrm{~d}, 2 \mathrm{H}, \mathrm{Ar}-\mathrm{H}), 7.8$ (d, $5 \mathrm{H},-\mathrm{CH}=\mathrm{CH}-, \mathrm{Ar}-\mathrm{H}), 8.1-8.2(\mathrm{~m}, 6 \mathrm{H}, \mathrm{Ar}-\mathrm{H})$. IR (nujol) $v \mathrm{~cm}^{-1}: 3367\left(-\mathrm{NH}_{2}\right), 1685,1729$ (COO), $1662(\mathrm{C}=\mathrm{O}$ in chalcone group), $1602(\mathrm{Ar}), 987$ $(-\mathrm{CH}=\mathrm{CH}-)$.

Anal. calcd for $\mathrm{C}_{65} \mathrm{H}_{74} \mathrm{~N}_{2} \mathrm{O}_{11}$ (1059.32), C73.70;
H7.04; N2.64. Found: C73.57; H7.11; N2.73.

Polyimide Derivative (PI-1) Containing 4,4'-(Hexafluoro-isopropylidene) Diphthalic Anhydride (6FDA) Derivative

4,4'-(Hexafluoroisopropylidene) diphthalic anhydride $(0.29 \mathrm{~g}, 0.65 \mathrm{mmol})$ and 4,4'-di(11-aminobenzoyloxyundecyloxy) chalcone $(0.53 \mathrm{~g}, 0.65 \mathrm{mmol})$ were dissolved in dry dimethylacetamide $(6.5 \mathrm{~mL})$. The reaction mixture was stirred for $48 \mathrm{~h}$ at room temperature under nitrogen atmosphere. After pyridine $(0.1 \mathrm{~mL})$ and acetic anhydride $(0.4 \mathrm{~g}, 3.9 \mathrm{mmol})$ were added to the reaction mixture, the reaction mixture was stirred at $70-80^{\circ} \mathrm{C}$ for $5 \mathrm{~h}$ using a Dean Stark apparatus. The reaction mixture was poured into a large amount of water. The solid obtained was dissolved in chloroform and then the polymer was purified by reprecipitation with methanol and then with acetone. The polymer was obtained in a $18.5 \%$ yield $(0.15 \mathrm{~g}) \cdot \bar{M}_{\mathrm{n}}=$ $42,300, \bar{M}_{\mathrm{w}} / \bar{M}_{\mathrm{n}}=1.65$.

IR (nujol) $v \mathrm{~cm}^{-1}: 1785(\mathrm{C}=\mathrm{O}$, imide ring), 1727 (COO), $1656(\mathrm{C}=\mathrm{O}$ in chalcone group), 1600, 1510 (Ar), $983(-\mathrm{CH}=\mathrm{CH}-)$.

\section{Polyimide Derivative (PI-2) Containing 6FDA Deriv- ative}

The polymer was prepared according to the same procedure as that of the polymer (PI-1). The polymer was obtained in a $24 \%$ yield $(0.23 \mathrm{~g}) \cdot \bar{M}_{\mathrm{n}}=20,600$, $\bar{M}_{\mathrm{w}} / \bar{M}_{\mathrm{n}}=1.79$.

Polyamic Acid (PAA-3) Containing 4,4'-Biphthalic Anhydride (BPDA) Derivative

$4,4^{\prime}$-Biphthalic anhydride $(0.26 \mathrm{~g}, 0.88 \mathrm{mmol})$ and 4,4'-di(11-aminobenzoyloxyundecyloxy) chalcone $(0.72 \mathrm{~g}, 0.87 \mathrm{mmol})$ were dissolved in dry dimethylacetamide $(6.5 \mathrm{~mL})$. The reaction mixture was stirred for $48 \mathrm{~h}$ at room temperature under nitrogen atmosphere. The reaction mixture was poured into a large amount of water. The precipitate obtained was dissolved in THF and then the polymer was purified by reprecipitation with ethylacetate. The polymer was obtained in a $51 \%$ yield $(0.5 \mathrm{~g}) \cdot \bar{M}_{\mathrm{n}}=14,800, \bar{M}_{\mathrm{w}} /$ $\bar{M}_{\mathrm{n}}=1.54$.

IR (nujol) $v \mathrm{~cm}^{-1}: 3297(\mathrm{~N}-\mathrm{H}), 2611(\mathrm{OH}, \mathrm{COOH})$, $1724(\mathrm{C}=\mathrm{O}, \mathrm{COO}, \mathrm{COOH}$ and amide groups), 1662 $(\mathrm{C}=\mathrm{O}$ in chalcone group), 1600 (Ar), $983(-\mathrm{CH}=$ $\mathrm{CH}-)$.

\section{Polyimide Derivative (PI-3) Containing BPDA Deriv-} ative

The spin-coated film was prepared using the THF solution (1 wt \%) of the polyamic acid (PAA3) containing 4,4'-biphthalic anhydride (BPDA) derivative. The polyimide in the film state was obtained by curing 
at $200^{\circ} \mathrm{C}$ under vacuum for $120 \mathrm{~min}$.

IR (nujol) $\nu \mathrm{cm}^{-1}: 1778(\mathrm{C}=\mathrm{O}$, imide group), 1718 $(\mathrm{C}=\mathrm{O}, \mathrm{COO}$ group$), 1662(\mathrm{C}=\mathrm{O}$, chalcone group $)$, 1600 (Ar), 1373 (C-N, imide group), $985(-\mathrm{CH}=$ $\mathrm{CH}-$, chalcone group).

\section{Polyamic Acid (PAA-4) Containing BPDA Derivative}

4,4'-Biphthalic anhydride $(0.144 \mathrm{~g}, 0.49 \mathrm{mmol})$ and 4,4'-di $\{4$-[11-(4-aminobenzoyl)undecyloxy]benzoyl $\}$ chalcone $(0.52 \mathrm{~g}, 0.49 \mathrm{mmol})$ were dissolved in $N$ methylpyroridinone $(10 \mathrm{~mL})$. The reaction mixture was stirred for $48 \mathrm{~h}$ at room temperature under nitrogen atmosphere. The reaction mixture was poured into a large amount of water. The precipitate obtained was dissolved in THF and then the polymer was purified by reprecipitation with methanol. The polymer was obtained in a $15 \%$ yield $(0.1 \mathrm{~g}) \cdot \bar{M}_{\mathrm{n}}=10,800, \bar{M}_{\mathrm{w}} /$ $\bar{M}_{\mathrm{n}}=1.83$.

IR (nujol) $v \mathrm{~cm}^{-1}: 3297(\mathrm{~N}-\mathrm{H}), 2611(\mathrm{OH}, \mathrm{COOH})$, $1724(\mathrm{C}=\mathrm{O}, \mathrm{COO}, \mathrm{COOH}$ and amide groups), 1662 $(\mathrm{C}=\mathrm{O}$, chalcone group), $1602(\mathrm{Ar}), 981(-\mathrm{CH}=\mathrm{CH}-)$.

\section{Polyimide Derivative (PI-4) Containing BPDA Deriv- ative}

The spin-coated film was prepared using the THF solution $(1 \mathrm{wt} \%)$ of the polyamic acid (PAA-4) containing 4,4'-biphthalic anhydride (BPDA) derivative. The polyimide in the film state was obtained by curing at $200^{\circ} \mathrm{C}$ under vacuum for $120 \mathrm{~min}$.

IR (nujol) $v \mathrm{~cm}^{-1}: 1778(\mathrm{C}=\mathrm{O}$, imide group), 1718 $(\mathrm{C}=\mathrm{O}, \mathrm{COO}$ group$), 1662(\mathrm{C}=\mathrm{O}$, chalcone group $)$, 1606 (Ar), 1373 (C-N, imide group), $985(-\mathrm{CH}=\mathrm{C}-$ $\mathrm{H}$, chalcone group).

\section{CHARACTERIZATION}

${ }^{1} \mathrm{H}$ NMR measurements were carried out with a JEOL JNM-LA 400 spectrometer using $\mathrm{CDCl}_{3}$ as the solvent. Infrared spectra were recorded on a JEOL JIR 7000 spectrometer with infrared microscope unit. Spectra were collected at $4 \mathrm{~cm}^{-1}$ resolution. Elemental analysis was carried out using a PerkinElmer Series II CHNS/O Analyzer 2400. DSC measurements were conducted with a Mettler DSC821 ${ }^{\mathrm{e}}$. TGA measurements were carried out with a Mettler TC10/ TA15. Optical microscopy was performed on a Nikon polarizing optical microscope, OPTIPHOTO-POL, equipped with a Mettler FP80 controller and a FP82 hot stage. Gel permeation chromatography (GPC) was carried out with a Tosoh HLC-8020 instrument using tetrahydrofuran as the eluent, equipped with three columns (TSK gel $\mathrm{GMH}_{\mathrm{XL}}, \mathrm{GMH}_{\mathrm{XL}}$ and $\mathrm{G}^{2} 2000 \mathrm{H}_{\mathrm{XL}}$ ). The instrument was calibrated with a polystyrene standard. X-ray diffraction patterns were recorded with a RIGAKU RINT2500 with Ni-filtered
$\mathrm{Cu}-\mathrm{K} \alpha$ radiation. The sample in quartz capillary (diameter $1 \mathrm{~mm}$ ) was held in a temperature-controlled cell (RIGAKU LC high temperature controller).

\section{RESULTS AND DISCUSSION}

\section{Synthesis and Solubility of Polyimides}

Generally, aromatic polyimides are important polymeric materials possessing outstanding thermal and mechanical properties. However the disadvantages of the polyimides are low solubility and poor processability. Therefore, the structural modification such as the introduction of bulky lateral substituents, flexible alkyl side chains, bent molecules and so on is investigated to enhance the solubility and the processability of the polyimides. ${ }^{25-30}$

Figure 1 displays the chemical structures of chalcone-based polyimides synthesized. The synthesis of the diamine derivatives was described in Schemes 1 and 2. The central core in the diamine derivative (12) is consisted of chalcone and two phenyl benzoate moieties. The diamine derivative (12) would have rigid nature compared to the diamine derivative (7). We already found that methacrylate polymers with a chalcone derivative (benzene-4-chalcone carboxylate) exhibited a smectic phase..$^{20,21}$ Therefore, we used the diamine derivative (12) containing a chalcone derivative similar to benzene-4-chalcone carboxylate to synthesize chalcone-based polyimides, although the diamine derivative itself did not exhibit any mesophases.

We employed conventional anhydrides like 6FDA or BPDA for the preparation of chalcone-based polyimides. To attach mesomorphic properties to chalcone-based polyimides, we used the rigid-rod anhydride (BPDA) with potential for a mesogenic group. ${ }^{31}$ On the other hand, the solubility is one of important parameters for polymeric materials. We employed 6FDA with the bent structure to prepare chalcone-based soluble polyimides, because the chemical structure of anhydrides would affect the solubility of polyimides. ${ }^{32}$

The imidization reaction was investigated by FT-IR measurements. Figure 2 shows the FT-IR spectra of PAA-3 and PI-3. In the FT-IR spectrum (a) of PI-3 prepared by the thermal imidization, the peaks near $1778 \mathrm{~cm}^{-1}$ and $1720 \mathrm{~cm}^{-1}$ characteristic of $\mathrm{C}=\mathrm{O}$ stretching of imide groups, and near $1373 \mathrm{~cm}^{-1}$ assigned to $\mathrm{C}-\mathrm{N}$ stretching of imide groups appear. The broad peak near $3300 \mathrm{~cm}^{-1}$ (N-H stretching) detected in the FT-IR spectrum (b) disappeared in the FT-IR spectrum (a). This result shows that the imidization reaction of PAA-3 would proceed almost perfectly. The same consideration concerning the FT-IR spectra of PAA-4 revealed that PI-4 also had the desired chemical structure of the polyimide. In the FT- 

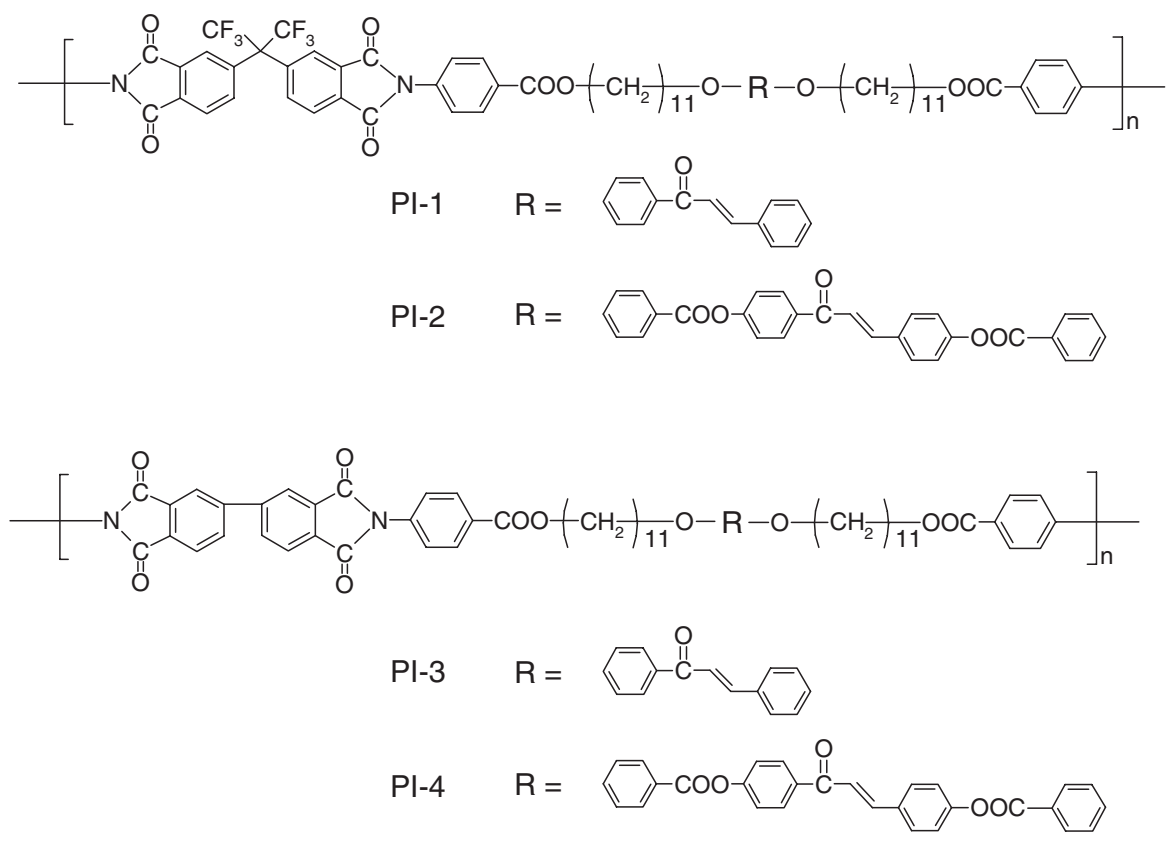

Figure 1. Chemical structures of main chain polyimides with a chalcone derivative.

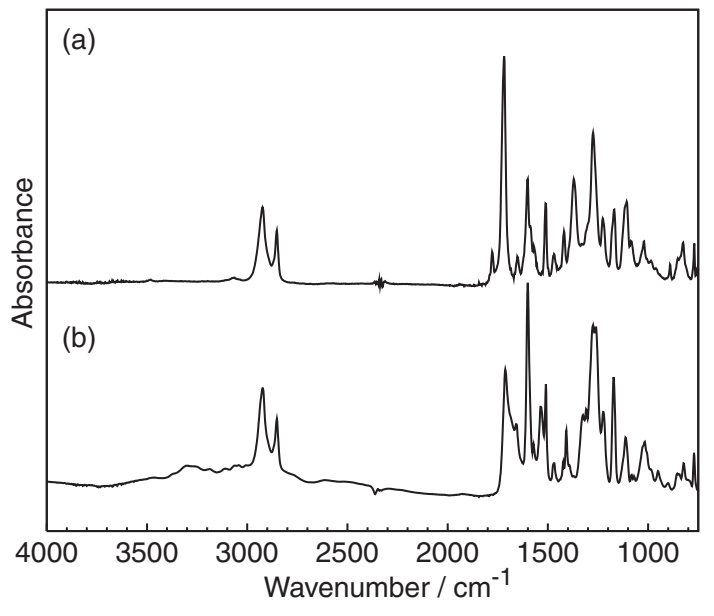

Figure 2. FT-IR spectra of polyimide (a) and polyamic acid (PAA-3) (b).

IR spectrum of PI-1 synthesized by the chemical imidization reaction, the peaks characteristic of the imide groups are also detected as shown in Figure 3.

The peaks characteristic of the trans chalcone moiety were observed near $985 \mathrm{~cm}^{-1}$ and near $1660 \mathrm{~cm}^{-1}$ in the FT-IR spectra. The shoulder peak near 985 and the small peak near $1660 \mathrm{~cm}^{-1}$ were assigned to the olefin $\mathrm{C}-\mathrm{H}$ out-of-plane bending and the ketone group, respectively. ${ }^{11}$ We investigated the thermal stability of the chalcone moiety by FT-IR measurements of the polyamic acids and polyimide films. The shoulder peak near $985 \mathrm{~cm}^{-1}$ and the small peak near $1660 \mathrm{~cm}^{-1}$ were observed in the FT-IR spectra of the polyamic acids. The peaks were also detected in the FT-IR spectra of the polyimides prepared by thermal

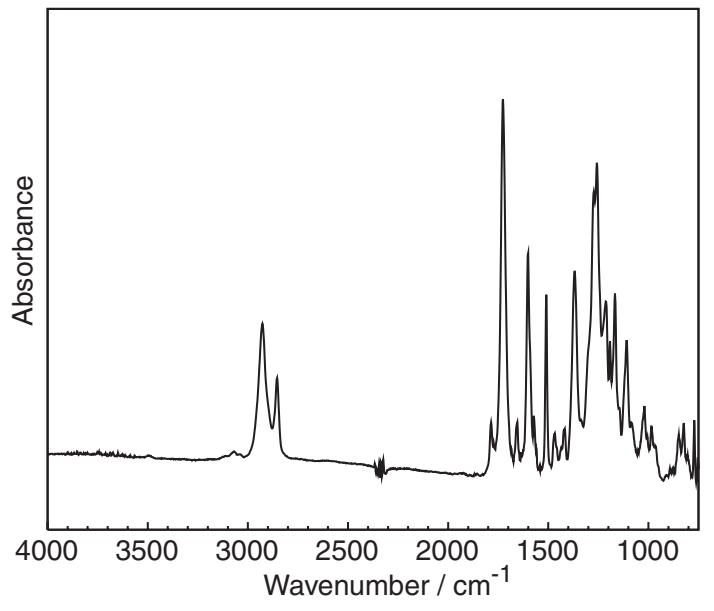

Figure 3. FT-IR spectrum of polyimide (PI-1).

curing reaction of relative polyamic acids. Furthermore, no changes of the peaks were also detected in the FT-IR spectra of the polyimides after annealing. These results support that the chalcone moiety in the polyimides is thermally stable.

PI-1 and PI-2 with 6FDA derivative were synthesized by chemical imidization reaction. PI-1 and PI2 are soluble in organic solvents such as tetrahydrofuran, chloroform and $\mathrm{N}, \mathrm{N}$-dimethylformamide as shown in Table I. On the other hand, PI-3 and PI-4 with BPDA derivative were obtained by thermal curing reaction of polyamic acids (PAA-3 and PAA-4). PAA-3 and PAA-4 were soluble in organic solvents such as tetrahydrofuran, chloroform and $N, N$-dimethylformamide. PAA-3 and PAA-4 in the film state were obtained by spin-coating of the THF solution of poly- 
Table I. Solubility of polymers

\begin{tabular}{ccccccccc}
\hline \multirow{2}{*}{ Polymers } & \multicolumn{8}{c}{ Solvents } \\
\cline { 2 - 8 } & $\mathrm{CHCl}_{3}$ & THF & DMF & DMSO & DMAc & NMP & Acetone & MeOH \\
\hline PI-1 & ++ & ++ & ++ & - & ++ & ++ & - & - \\
PI-2 & ++ & ++ & ++ & - & ++ & ++ & - & - \\
PI-3 & - & - & - & - & - & - & - & - \\
PI-4 & - & - & - & - & - & - & - & - \\
PAA-3 & - & ++ & ++ & + & ++ & ++ & - & - \\
PAA-4 & - & ++ & ++ & + & ++ & ++ & - & - \\
\hline
\end{tabular}

Qualitative solubility was determined with $1 \mathrm{mg}$ of polyimide in $1 \mathrm{~mL}$ of solvent ++ ; soluble at room temperature, + ; soluble on heating $\left(60^{\circ} \mathrm{C}\right),-$; insoluble

amid acids ( $1 \mathrm{wt} \%)$ on the glass substrate. PI-3 and PI-4 prepared by thermal curing reaction of PAA3 and PAA4 were insoluble in common organic solvents.

In our preliminary experiments, PI-3 with BPDA derivative was synthesized by chemical imidization reaction. PI-3 was obtained as a precipitate during the chemical imidization reaction of PAA-3, because PI-3 was insoluble in common organic solvents. Glass transition temperature of PI-3 obtained by chemical imidization reaction was similar to that of PI-3 prepared by thermal curing reaction, however, the clearing point of PI-3 obtained by chemical imidization reaction was lower than that of PI-3 prepared by thermal curing reaction. It was difficult to make a thin film of PI-3 obtained by chemical imidization reaction because of poor solubility of PI-3 in common organic solvents. Therefore, we synthesized PI-3 and PI-4 according to the conventional thermal curing reaction of PAA-3 and PAA-4, respectively.

In spite of the employment of the diamine derivative with flexible alkyl chains, the resulting PI-3 and PI-4 were insoluble in common organic solvents. This result indicated that the chemical structure of the anhydride would deeply influence the solubility of the resulting polyimides. The solubility of PI-1 and PI-2 would depend upon the bent structure of the anhydride derivative (6FDA) containing $\mathrm{sp}^{3}$ carbon.

\section{Thermal Properties of Polyimides}

Molecular weights and thermal properties of the polyimides are summarized in Table II. Birefringence was not observed for PI-1 and PI-2. Only a shift of the baseline was detected in the DSC curve of PI- 1 and PI-2. We concluded that PI-1 and PI-2 do not exhibit any mesophases based upon the results of polarized optical microscopy and DSC measurements. Thermal decomposition temperatures of PI-1 and PI-2 were 340 and $380^{\circ} \mathrm{C}$, respectively.

The optical textures characteristic of liquid crystals were not observed for PI-3 and PI-4, however, birefringence was detected for the polyimides. No appear-
Table II. Molecular weights and thermal properties of polyimides

\begin{tabular}{clccc}
\hline Polymers & \multicolumn{1}{c}{$\begin{array}{c}\text { Thermal behavior } \\
\left({ }^{\circ} \mathrm{C}\right)\end{array}$} & $\begin{array}{c}T_{\mathrm{d}}^{\mathrm{a}} \\
\left({ }^{\circ} \mathrm{C}\right)\end{array}$ & $\bar{M}_{\mathrm{n}}$ & $\bar{M}_{\mathrm{w}} / \bar{M}_{\mathrm{n}}$ \\
\hline PI-1 & $T_{\mathrm{g}} ; 110$ & 340 & 42,300 & 1.65 \\
PI-2 & $T_{\mathrm{g}} ; 107$ & 380 & 20,600 & 1.79 \\
PI-3 & $\mathrm{g} \underset{81}{\stackrel{87}{\rightleftarrows}} \mathrm{Sm} \underset{210}{\stackrel{229}{\rightleftarrows} \mathrm{I}}$ & 340 & - & - \\
PI-4 & $\mathrm{g} \stackrel{96}{\rightarrow} \mathrm{Sm} \rightarrow$ Decomp. & 310 & - & - \\
\hline
\end{tabular}

${ }^{\text {a }}$ Temperatures at which $10 \%$ weight loss was recorded by TGA measurements. g; glassy, Sm; smectic phase, I; isotropic phase, Decomp.; thermal decomposition, $T_{\mathrm{g}}$; glass transition temperature

ance of optical textures characteristic of liquid crystals (smectic phase) may originate from the orientation of main chains of the polyimides that were prepared by thermal curing reaction of polyamic acids drawn by rotation of spin-coating method. However, at the present time, we can not clarify the reason why the optical textures characteristic of liquid crystals (smectic phase) can not be detected by polarized optical microscopy measurements of the polyimides. We were not able to observe the optical textures characteristic of liquid crystals (smectic phase), even if the polyimides were annealed in the mesomorphic temperature range and even if we investigated optical textures of the samples in different thickness by polarized optical microscopy measurements.

Figure 4 shows the DSC curves of PI- 3 and PI-4 on the heating scan. The shift of the baseline and the endothermic peak were observed in the DSC curve of PI-3. The shift of the baseline was attributed to the glass transition temperature, and the endothermic peak was assigned to the clearing temperature (mesophaseisotropic phase transition temperature). The mesophase-isotropic phase transition temperatures were supported by the optical microscopy observation of PI-3. Birefringence of PI-3 disappeared at the clearing temperature. In the DSC curve of PI-4, only a shift of the baseline was detected. A typical texture for liquid crystals was not shown for PI-4, however birefrin- 


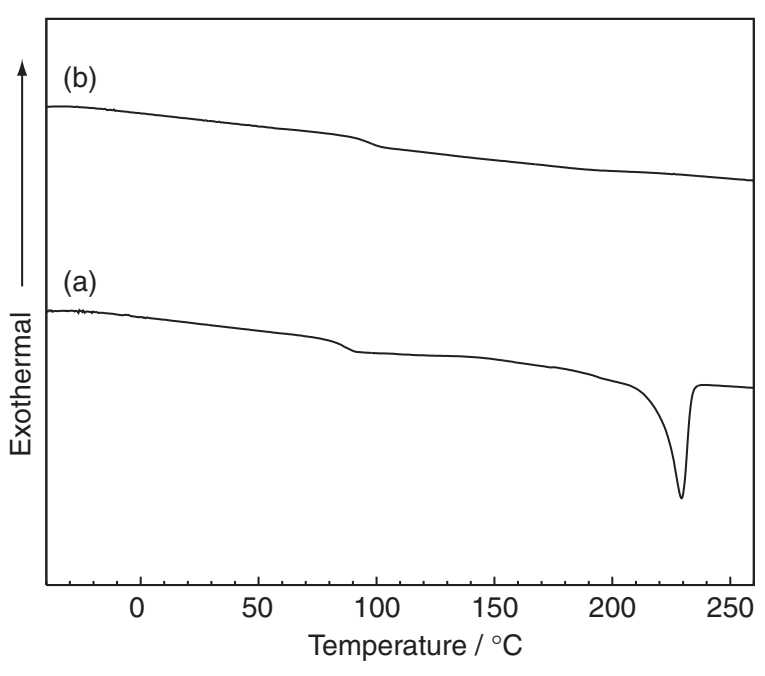

Figure 4. DSC curves of PI-3 (a) and PI-4 (b) on heating scan.

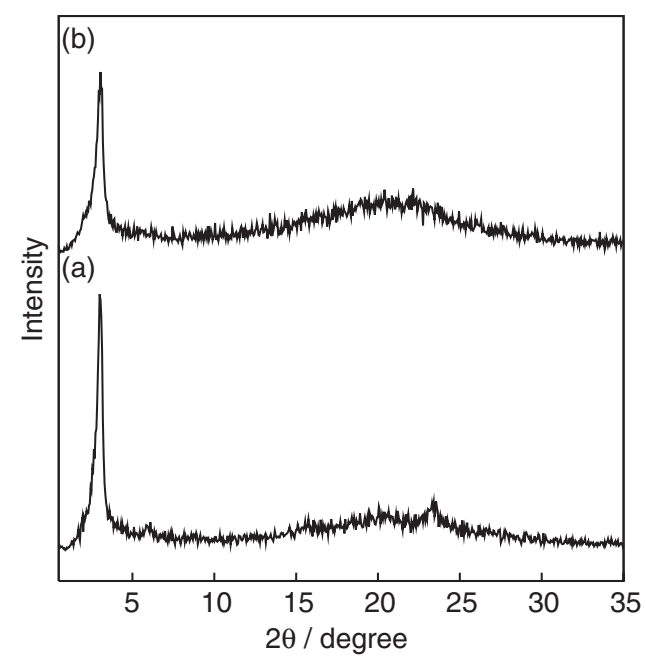

Figure 5. X-ray patterns of PI-3 at room temperature (a) and at $140{ }^{\circ} \mathrm{C}$ (b).

gence was observed. Therefore we conclude that PI-4 exhibits a mesophase above glass transition temperature. Further heating PI-4 leads to the thermal decomposition before the phase transition to the isotropic melt.

Figure 5a displays the X-ray diffraction pattern of PI-3 at room temperature. The signal-to-noise ratio of $\mathrm{X}$-ray patterns as shown in Figure 5 may be relatively low. However, we determined the liquid crystal phase structures of the polyimides with BPDA derivative according to consideration as described in the following explanation. A sharp peak at $3.0^{\circ}(d$-spacing $29.4 \AA)$ and a small peak at $6.0^{\circ}$ were shown in the X-ray diffraction pattern. The diffraction peaks in the small-angle region would be attributed to the layer structure of PI-3. A broad peak near $20^{\circ}$ and a small peak at $23.4^{\circ}$ are also detected in the X-ray diffraction pattern at room temperature. The diffraction peaks in the wideangle region are based upon the lateral interaction of
PI-3. The appearance of the small peak at $23.4^{\circ}$ would suggest the highly ordered structure in the lateral direction of PI-3 below glass transition temperature.

Figure $5 \mathrm{~b}$ displays the $\mathrm{X}$-ray diffraction pattern of PI- 3 at $140{ }^{\circ} \mathrm{C}$. A sharp peak in the small-angle region (at $3.0^{\circ}$ ) and a broad peak in the wide-angle region were detected in the X-ray diffraction pattern. This $\mathrm{X}$-ray diffraction pattern indicates the structure of the mesophase would be a smectic phase. The layer spacing of the smectic phase of PI-3 is the same as that below glass transition temperature. The appearance of the broad peak in the wide-angle region shows that the highly order due to the lateral interaction of PI-3 below glass transition temperature is lost in the smectic phase.

The X-ray diffraction pattern of PI-4 was similar to that of PI-3. The $d$-spacing based upon the sharp peak in the small-angle region was $32.7 \AA$. The $d$-spacing of PI-4 was longer than that of PI-3. The result of the X-ray diffraction measurements displays that PI4 also exhibits a smectic phase. The BPDA derivative in PI-3 and PI-4 would be a mesogenic group, because PI-1 and PI-2, which have the 6FDA derivative and the same chalcone derivative as PI-3 and PI-4, did not show any mesophases. ${ }^{31}$ The origin of the $d$-spacing based upon the sharp peak in the small-angle region $(29.4 \AA$ and $32.7 \AA$ for PI-3 and PI-4, respectively) is not clarified at the present time. However, each $d$-spacing is related to half of the calculated length of the repeating unit in each polyimide.

We investigated the photo-alignment behavior of low molecular liquid crystal in the LC cell fabricated from the polyimide film irradiated with linearly polarized UV light. Details of the photo-alignment behavior of low molecular liquid crystal will be reported in the near future.

\section{REFERENCES}

1. K. Ichimura, Chem. Rev., 100, 1847 (2000).

2. M. O'Neill and S. M. Kelly, J. Phys. D: Appl. Phys., 33, R67 (2000).

3. K. Ichimura, Y. Hayashi, H. Akiyama, T. Ikeda, and N. Ishizuki, Appl. Phys. Lett., 63, 449 (1993).

4. T. Seki, K. Ichimura, R. Fukuda, T. Tanigaki, and T. Tamale, Macromolecules, 29, 892 (1996).

5. K. Ichimura, H. Akiyama, K. Kudo, N. Ishizuki, and S. Yamamura, Liq. Cryst., 20, 423 (1996).

6. M. Schadt, K. Scmitt, V. Kozinkov, and V. Chigrinov, Jpn. J. Appl. Phys., 31, 2155 (1992).

7. Y. Iimura, T. Saitoh, S. Kobayashi, and T. Hashimoto, J. Photopolym. Sci. Technol., 2, 257 (1995).

8. X. Li, D. H. Pei, S. Kobayashi, and Y. Iimura, Jpn. J. Appl. Phys., 36, L432 (1997).

9. K. Ichimura, Y. Akita, H. Akiyama, K. Kudo, and Y. Hayashi, Macromolecules, 30, 903 (1997). 
10. G. P. Bryan-brown and I. C. Sage, Liq. Cryst., 20, 825 (1996).

11. Y. Makita, T. Ogawa, S. Kimura, M. Nakata, S. Kimura, Y. Matsuki, and Y. Takeuchi, IDW '97, FMC3-3, 363 (1997).

12. Y. Makita, T. Natsui, S. Kimura, S. Nakata, M. Kimura, Y. Matsuki, and Y. Takeuchi, J. Photopolym. Sci. Technol., 11, 187 (1998).

13. Y. Makita, T. Natsui, S. Kimura, M. Nakata, S. Kimura, Y. Matsuki, and Y. Takeuchi, SID 98 Dig., LP-H, 750 (1998).

14. S. Nakata, K. Kuriyama, M. Kimura, T. Natsui, Y. Makita, Y. Matsuki, N. Bessho, and Y. Takeuchi, SID 99 Dig., LP-3, 512 (1999).

15. D.-S. Seo and J.-Y. Hwang, Jpn. J. Appl. Phys., 39, L816 (2000).

16. D.-S. Seo and J.-Y. Hwang, Jpn. J. Appl. Phys., 39, L1239 (2000).

17. M. Kimura, S. Nakata, Y. Makita, Y. Matsuki, A. Kumano, Y. Takeuchi, and H. Yokoyama, Jpn. J. Appl. Phys., 40, L352 (2001).

18. N. Kawatsuki, H. Takatsuka, T. Yamamoto, and H. Ono, Jpn. J. Appl. Phys., 36, 6464 (1997).

19. N. Kawatsuki, K. Takatani, T. Yamamoto, and H. Ono, Polym. J., 30, 946 (1998).

20. T. Mihara, M. Tsutsumi, and N. Koide, Mol. Cryst. Liq. Cryst., 382, 53 (2002).
21. T. Mihara, M. Tsutsumi, and N. Koide, Polym. J., 34, 347 (2002).

22. T. Mihara, M. Tsutsumi, and N. Koide, Mol. Cryst. Liq. Cryst., 412, 247 (2004).

23. K. Feng, M. Tsushima, T. Matsumoto, and T. Kurosaki, J. Polym. Sci., Part A: Polym. Chem., 36, 685 (1998).

24. D. H. Choi, S. J. Oh, H. B. Cha, and J. Y. Lee, Eur. Polym. J., 37, 1951 (2001).

25. D. S. Reddy, C.-H. Chou, C.-F. Shu, and G.-H. Lee, Polymer, 44, 557 (2003).

26. H. B. Zheng and Z. Y. Wang, Macromolecules, 33, 4310 (2000).

27. D.-J. Liaw, B.-Y. Liaw, and C.-Y. Chung, J. Polym. Sci., Part A: Polym. Chem., 37, 2815 (1999).

28. S. L. Liu, T. S. Chung, L. Lu, Y. Torii, H. Oikawa, and A. Yamaguchi, J. Polym. Sci., Part B: Polym. Phys., 36, 1679 (1998).

29. B. Li, T. He, and Mengxian, Thin Solid Films, 320, 280 (1998).

30. T. L. Grubb, V. L. Ulery, T. J. Smith, G. L. Tullos, H. Yagci, L. J. Mathias, and M. Langsam, Polymer, 40, 4279 (1999).

31. H. R. Kricheldorf, M. Rabenstein, and G. Schwarz, J. Polym. Sci. Part A: Polym. Chem., 38, 3019 (2000).

32. J. Yin, Y.-F. Ye, and Z.-G. Wang, Eur. Polym. J., 34, 1839 (1998). 